\title{
Job Satisfaction Components and Turnover Intention at Selected Automotive Manufacturing Facility in Malaysia
}

\author{
Nurazree Mahmud ${ }^{1}$, Intan Syafinaz Mustapha ${ }^{2}$, Noorshuhana Mohd Adom³ , Nur'ain Abu \\ Mansor $^{4}$ \\ \{nurazree642@uitm.edu.my ${ }^{1}$ \}
}

Universiti Teknologi MARA, Malaysia ${ }^{1,2,3,4}$

\begin{abstract}
Turnover has become a crucial problem in organization and it has impacted the employee performance as well as the whole organization's performance. The objectives of this study aim to focus on the turnover issue of the employee at selected automotive manufacturing facility in Malaysia. Questionnaires and document analysis were blended to capture authenticity and exhaustiveness of the data. 80 participants were selected from employees of the said organization. Both inferential and descriptive statistics were used to present the results. Next, the data collection in this study was also analyzed by using frequency, descriptive analysis, reliability, Pearson's Correlation analysis and Multiple Regression Analysis in order to answer the research questions. The researchers have found that out of four components of job satisfaction that were chosen for this study, the only one factor that is significant on the employee turnover intention is nature of work. Another three-factor (supervision, salary and welfare) have no significant impact on employee turnover intention in the case of this organization. In other words, this organization needs to put serious effort in order to have a better nature of work thus will reduce turnover intention among its employees.
\end{abstract}

Keywords: Job Satisfaction Components, Turnover Intention, Organization, Nature Of Work

\section{Introduction}

Employee turnover has been a concern for all businesses, especially in the $21^{\text {st }}$ century [1] There are several impacts with this turnover and one of this impact is related with employee replacement costs that normally range from $90 \%-100 \%$ of an employee's annual salary [2]. The general business problem is that business owners often faced is unable to retain employees, which negatively impacts company profits [3]. The specific business problem is that some small business owners still do not understand the relationship between employee turnover intentions and job satisfaction of their employees. When workers are dissatisfied, they tend to move elsewhere to seek satisfaction. Large number of employees' turnover can lead to a lot of problems, such as cost increase in recruiting and training new employees, increase in workload and organizational inefficiency. To achieve high performance and high productivity levels, organizations must receive the contributions and support of their employees. Several literatures have been widely discussed the idea of employee job satisfaction because few researchers and experts believe that it can affect employee productivity and turnover. 
The automotive manufacturing industry is a major industrial and economic force worldwide. The industry is made up of companies and workers who are involved in the production of passenger automobiles, light trucks, pickups, vans, and sport utility vehicles (SUV). In addition to manufacturers, this sector includes the manufacturers and resellers of auto parts, engines and bodies, third-party servicing companies, manufacturers of trailers and tire stores, sales and after sales care. On a global basis, world leaders of car production include Toyota, Mercedes-Benz, Ford, Audi, Honda and Volkswagen. The industry also has created high technology value in businesses and talented individuals, who now can participate in vehicle \& component design, manufacturing, quality management, vehicle service \& repairs as well as new sectors such as recycling and remanufacturing.

According to business advising firm Schneider Downs, one of the biggest human resources challenges in the auto industry is the fact that many automotive businesses lack a "comprehensive, step-by-step action plan to become an employer of choice". In other words, automotive businesses struggle with major human resources functions because they do not have a strategic, focused plan that involves hiring, training, delegating, promoting and releasing employees. Because they do not have strategic plans, Schneider Downs argues that most automotive businesses operate without both the strategies needed to find the right talent and the processes required to maximize their impact [4].

Employee turnover in an organization is a very common issue. People or employees will come and go from one company to another for many factors. In the automotive industry, employee turnover costs dealers billions [5]. Wilson also added that few dealers are trained on how to hire, but as more face up to the implications of the problem. They are starting to search for new perspective with the task and experiment with new approaches. In addition, high staff turnover has been a serious phenomenon facing by management in many organizations. Clarke [6], shows that employment in manufacturing industry heavily contribute to job dissatisfaction and significantly contribute for high turnover which will affect the firm's goal and objectives in a long run. With regards to several issues that have been highlighted before, this study explores the components of job satisfaction and tries to established its relationship with employee's turnover intentions, in return will retain long-term business success in automotive manufacturing industry in Malaysia.

\section{Literature Review}

Turnover of employee is the rate of staff recruitment and rate of staff leaving an organization. According to Aydogd and Asikgil [7], turnover intention is based on behaviour of employees that has an intention to withdraw from their organization. Referring to Medina [8], that turnover intention is the employee's consideration to look for a new job opportunity. It can be a measurement of whether a business or organization's employees plan to leave their positions or whether that organization plans to remove employees from positions. Job satisfaction is seen as a common behaviour of employees and normally it based on several factors related to their nature of work, place and some approaches of work that they conducted, in which this level of satisfaction also will influence to the performance [9]. This study focused on the four factor of job satisfaction namely supervision, nature of work, welfares and pay/salary which influence the employee turnover intention. 


\subsection{Supervision}

Supervision as defined by Winston and Creamer [10] as "a management function intended to promote the achievement of institutional goals and enhance the personal and professional capabilities of staff. Supervision interprets the institutional mission and focuses human and fiscal resources on the promotion of individual and organizational competence" (p. 42).

As referred to Alkhateri et al. [11], the perceived supervisor support become the main backbone to reduce the turnover intention among the employees and the organization need to enhance the support among the staff, in return self-efficacy also will be supported. Perceived supervisor support is valuable factor that have the potential to create strategic ways for turnover management and organizations must pay attention to foster this support in order to reduce turnover intentions [12]. In addition, the quality of supervision also plays such an important to meet the employee satisfaction. According to Shukla [13] the quality of the supervision that an employee receives is critical to employee retention and some people leave the top-level managers and immediate supervisors more often than they leave job or the organizations. The character of supervisor is crucial even though they have a very good character any pleased by others, every single supervisor need to have clear expectations and critical role of the employee, in return to spur retention among employees. Other than that, it will contribute to turnover if the supervisors do not play important roles to enhance the positive value to the subordinates.

H1: There is a relationship between supervision and employee turnover intention.

\subsection{Nature of work}

The nature of work covers the work environment and types of job responsibilities and employee faced in an organization. It includes the extent of fairness and equity of the salary given [14]. According to Jared [15], nature of work refers to the basic daily tasks carried out as part of a job and refer to other non-routine tasks that may be required. Employee performs their duties and daily activities in workplace environment. Commonly noise level, fresh air and incentives like child care also become a part of work environment. Workplace surroundings may have positive or negative impact on the satisfaction level of employee's subject upon the nature of working environment [16]. Nature of work that might associate with working condition may influence the employee's emotion and resulted intention to leave the organization voluntarily [17]. Many researchers hold the point that employees leave their jobs when their needs are not being satisfied and the nature of work are not meet their expectation during their current job and an alternative job becomes available.

$\mathrm{H} 2$ : There is a relationship between nature of work and employee turnover intention.

\subsection{Salary}

Salary is primary concern to both employers and employees. For employees, salary is importance in term of satisfying their economic needs [18]. Thus, the satisfaction with regards to this pay system need to be achieved as this factor might contribute to the positive attitude and behavior towards organization. Heneman and Judge [19] stated that salary dissatisfaction can have important and undesirable impacts on numerous employee outcomes. Employees who are dissatisfaction with their salary, for instance, can decrease commitment to the job and cause turnover. 
The higher the salary that employee received, the higher the job satisfaction and lower their intention to leave the organization. It is supported by Lee et al. [20], the finding of the research showed that the higher the salary level will lead to higher satisfaction and organizational commitment level. In return, this will be indirectly resulted to the lower the employee turnover intention. These finding are in line with other previous studies carried out by Hayes [21] that employee's level of income and turnover intention has a significant relationship that when income increased, turnover intention decreased. Iqbal et al. [22] found that a high level of salary resulted higher job satisfaction. Hence, in return this will become a point of attraction for organization to retain quality employees. Salary satisfaction means comprehensive personal attitude or feeling toward their own salary, whether it was a positive or a negative feeling. Salary satisfaction is often thought to affect behaviour, such as absence and turnover intention. In the research studied by Hung et. al. [23], they found that there has a significant relationship between salary satisfaction and turnover intention and this relationship also associated with the working pressure and its effect to turnover intention among the employees.

H3: There is a relationship between salary and employee turnover intention.

\subsection{Welfares}

According to Todd [24] employee's welfare means anything made for comfort and improvement, intellectual or social of the employees more than wages paid which is not a necessity of the industry. Employee welfare is the non-cash compensation that provides to all employees, such as health insurance, retirement plan, vacation pay, life insurance and rewards. Many employees are expected to receive this kind of benefit from their employer, which is failure to provide this benefit to the employee can make them to more likely to leave for a better opportunity. Employee's welfare is important that lead to the job satisfaction in the workplace.

Employee welfare is considered valuable to the organization as this element will become one of the sources of job motivation and will turn into job satisfaction. Each organization urged to enhance on employee welfares by channeling some resources and at last will created the good organizational value and become one of the organizational identifications to retain the employees [25].

Employee welfare is the benefits that the company provides to all the employees in the organization, including health and safety, compensation, remuneration and rewards. There are several studies shows that employee welfare such as benefit and job safety are related to the job satisfaction thus will become as one of the factors that lead turnover intention. As mentioned by Javed et al. [26], rewards also are very strongly correlated to job satisfaction. A reward has been mentioned by many researchers that it was a part of employee welfare, that it was a factor that may lead to the turnover intention among employee of an organization. This study also supported by Sukriket [16] that benefit has a significant relationship that influenced employee's turnover intention in organization. Moreover, another element of welfares related to employees can also be viewed in terms of occupational safety and health system in organization. In the study by Liu et al. [27], providing good employee welfare such as a better health and safety system in the organization tends to increase their commitment in organization and have low turnover intention.

H4: There is a relationship between welfares and employee turnover intention. 


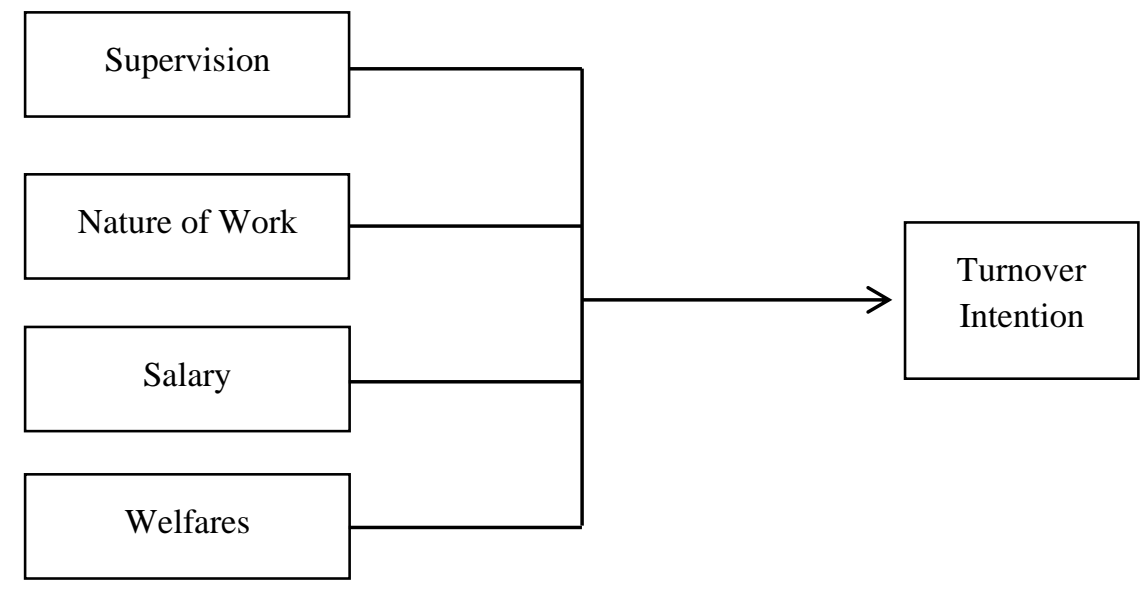

Independent variables

Dependent variable

\section{Methodology}

\subsection{Sample}

In this study, the referred sample comprises of a total of 80 employees from one selected automotive manufacturing company in Melaka, Malaysia. 100 questionnaires distributed to the respondents. However, 20 questionnaires were unable to be retrieved back, in which the respondent failed to return. The collection periods of this study conducted from 15th April 2019 to 15 th May 2019.

This study uses non-probability sampling in collecting data from the sample. Based on the certain limitation, quota sampling technique was chosen without affecting/interfering much of the accuracy of the data.

\subsection{Data Collection and Instruments}

This research has chosen to use questionnaire. The variables in the questionnaire are in close-ended set of questions and analyzed using statistically and numerically. The questionnaire formed was designed in paper form and distributed in accordance to the availability and preference of the approached employee as respondents. To analyze the data from the preliminary study, the IBM SPSS Statistic version 22 was employed. Three statistical analysis were executed including Descriptive Analysis for the respondent profile, Cronbach's alpha analysis for reliability and multiple regression analysis for hypotheses testing.

The questionnaire prepared in this research consists of five sections and a total of 36 items altogether. The first section of the questionnaire is Section A, represents the Demographic questions to obtain respondents' profiles. It includes age, gender, level of education, monthly salary, years of working experience and intention to leave status. Section B comprises questions regarding the dependent variable of this study in which is turnover intention. Whereas, Section $\mathrm{C}, \mathrm{D}, \mathrm{E}$ and $\mathrm{F}$ represents questions pertaining the independent variables - supervision, nature of 
work, salary and welfares, respectively. Section B to F were designed in the form of five-point Likert Scale ranging from 1 to 5 , with $1=$ Strongly Disagree. $2=$ Disagree, $3=$ Neither Agree nor Disagree, $4=$ Agree, $5=$ Strongly Agree. All items were adapted from previous researches for instance Bothma \& Roodt [28], San Park \& Kim [29], Azanza et al. [30], Sukriket [16], Mbah \& Ikemefuna [31], Ncede [32], Njeru [33].

\section{Result and Discussion}

\subsection{Reliability Analysis}

Table 1 shows the value of Cronbach's Alpha and all variables are accepted as the Cronbach alpha more than 0.6 [34]. The highest is salary with alpha value 0.895 and the lowest is Nature of Work with alpha value 0.677 but still accepted. Overall, based on the Cronbach's alpha coefficient for all constructs are more than 0.6 , it can indicate that the measurement scales for various constructs were reliable and consistent for each variable in measuring the constructs.

Table 1. Reliability analysis

\begin{tabular}{lcc}
\hline \multicolumn{1}{c}{ Variable } & Number of items & Cronbach's Alpha \\
\hline Turnover Intention & 6 & 0.860 \\
Supervision & 6 & 0.884 \\
Welfare & 6 & 0.868 \\
Salary & 6 & 0.895 \\
Nature of Work & 6 & 0.677 \\
\hline
\end{tabular}

\subsection{Demographic Profile of Respondents}

Table 2 below shows the profile of respondents. First dimension of measurement in the demographic profile indicates the respondent's age. All the respondents had been grouped into four (4) categories to determine the precision of the respondent's age. $77.5 \%$ of the respondents are $20-30$ years old. $11.3 \%$ of the respondents are $31-40$ years old. $6.3 \%$ of the respondents are less than 20 years old and the lowest one is more than 40 years which is only $5 \%$ of the total respondents. This shows that majority of the respondents is in the age of 20-30 years old. Next distribution of respondent is gender. It shows most of the respondent is female $(57.5 \%)$ and the remaining respondent is male $(42.5 \%)$. It shows that the number of the female respondents is more than the male respondents. Third dimension is the respondent's education level. All the respondents had been grouped into four (4) categories to determine the precision of the respondent's education level. $35 \%$ of the respondents have a Degree. $31.3 \%$ of the respondents have a Diploma. 26.3\% have SPM. This shows that the highest number of respondent's education level is from Degree. Next is the intention to leave among employees. $71.3 \%$ of the respondents have intention to leave the company the remaining $28.8 \%$ have no intention to leave. This means that majority of the respondent's intent to leave the company. As for the working experience, it shows that most of the respondents $(66.3 \%)$ are within the range of 1 to 5 years and only $5 \%$ of the respondents worked more than 10 years. The last one is salary. $85 \%$ of the respondents' salary within the range of RM1, 000-RM3, 000 and the lowest percentage is $1.3 \%$ which is more than RM5, 000. All in all, it is also showing that less than RM3, 000 monthly salary is the higher contributor in this table. 
Table 2. Respondents profile

\begin{tabular}{|c|c|c|c|}
\hline \multicolumn{2}{|c|}{ Items } & Frequency & Percentage \\
\hline \multirow{4}{*}{ Age } & Less than 20 & 5 & 6.3 \\
\hline & $20-30$ & 62 & 77.5 \\
\hline & $31-40$ & 9 & 11.3 \\
\hline & More than 40 years & 4 & 5.0 \\
\hline \multirow{2}{*}{ Gender } & Male & 34 & 42.5 \\
\hline & Female & 46 & 57.5 \\
\hline \multirow{4}{*}{ Education } & SPM & 21 & 26.3 \\
\hline & Diploma & 25 & 31.3 \\
\hline & Degree & 28 & 35.0 \\
\hline & Others & 6 & 7.5 \\
\hline \multirow{2}{*}{ Intention to leave } & Yes & 57 & 71.3 \\
\hline & No & 23 & 28.8 \\
\hline \multirow{4}{*}{ Working Experience } & $<1$ year & 14 & 17.5 \\
\hline & $1-5$ years & 53 & 66.3 \\
\hline & $6-10$ years & 9 & 11.3 \\
\hline & $>10$ years & 4 & 5.0 \\
\hline \multirow{4}{*}{ Monthly Salary (RM) } & $<1000$ & 5 & 6.3 \\
\hline & $1001-3000$ & 68 & 85.0 \\
\hline & $3001-5000$ & 6 & 7.5 \\
\hline & $>5000$ & 1 & 1.3 \\
\hline
\end{tabular}

\subsection{Multiple Regression Analysis}

The multiple regression analysis was analyzed through the questionnaire distributed to the employees. The result of the analysis measured by the value of $\mathrm{R}^{2}$, the value of F-test in Anova table and the value of standardized coefficient beta, $\beta$. The results of multiple regressions are presented in Table 3.

From the regression result, the value of $\mathrm{R}^{2}$ is 0.326 which showed that only $32.6 \%$ of the changes in the turnover intention were explained by the changes in the independent variables included in this study which are nature of work, supervision, welfares and salary. This means that the remaining $67.4 \%$ of the predictors is determined from other variable factors to explain dependent variable that are not included in this research. While, for the F value, the value is 9.074, it indicated that the model is significant due to the $\mathrm{F}$ value is significant at 1 percent significant level and the significant value is less than 0.05 .

Table 3. Result of multiple regressions

Dependent variable: Turnover Intention

\begin{tabular}{lcc}
\hline \multicolumn{3}{c}{ Dependent variable: Turnover Intention } \\
\hline \multicolumn{1}{c}{ Independent variables } & $\begin{array}{c}\text { Standardized Coefficient } \\
\text { (BETA) }\end{array}$ & Sig. \\
\hline (Constant) & 5.432 & 0.000 \\
Supervision & -.181 & 0.930 \\
Welfares & -.051 & 0.703 \\
Salary & -.234 & 0.110 \\
Nature of Work & -.257 & 0.029 \\
F value & $(9.074) 0.000$ & \\
R square & \multicolumn{2}{c}{0.326} \\
\hline
\end{tabular}


Based on the Table 3 above, the only variable having significant relationship is Nature of Work which is the significant value is 0.029 as it is less than 0.05 . The beta value of nature of work $(\beta=-0.257)$ also indicated that nature of work is the highest predictor among the other independent variables. The result also specifies the negative relationship of the nature of work toward the turnover intention which the increase of one unit of nature of work may decrease some value of turnover intention.

However, for the other three independent variables - supervision, welfares and salary, the results turned out to be not significant at the value of $0.930,0.703$ and 0.110 respectively, as they are not within $p<0.01$ or even $p<0.05$. These variables also had low beta value with welfares being the lowest at a negative value (-0.051). This means that those three variables were not significantly influence the dependent variable, turnover intention in this research.

\section{Implication and Conclusion}

Based on this empirical evidence, this is proved that nature of work is the only factor that leads to turnover intention for this case. This is also consistent with other previous studies (for instance; Sukriket [16] and Ahmad [17] in which the nature of work having significant impact toward turnover intention. This is also can be concluded that, if the employer can provide a better work environment, employee job satisfaction can be effectively improved, thus reducing the turnover rate.

Meanwhile, the first independent variable which is Supervision, it indicates no significant relationship towards turnover intention. This result is consistent to the research by Adebayo and Ogunsina [35] that found there is no interaction influence of supervision on turnover intention. This might be due to the nature of this organization had a good leader with effective leadership styles that the employees did not feel any lack of supervision by their superior. This is also similar to welfares; this research shows no significant relationship on welfares and it indicates that the employee will not be influenced by the welfare in having the turnover intention. It means that they are satisfied with the welfare given by this organization. As for the salary, this factor also insignificant with turnover intention and consistent with findings from the previous research by Ikatrinasari et al. [36], Sukriket [16] and Chepchumba and Kimutai [37]. This may because referring to the location of this organization in which the factory is located in low living cost area and their salary may enough for their expenses for basic need and lifestyles.

With regards to the nature of work that influence turnover intention, there are several actions need to be taken in order to reduce this issue among automotive workers given in this setting. For instance, by improving working facilities via the assistance of government funding that is allocated for SME and Bumiputera company such as Bumiputera Enterprise Enhancement Program (BEEP), Micro Enterprise Fund (MEF) and SME Scheme (Service, Manufacturing and Enterprise) and utilize it for the improvements of the company facilities thus will overcome their nature of work issues. It is important for each manufacturer to put more attention on the facilities as a healthy work environment brings safety to employees' physical and mental capabilities in performing their daily routine. In addition, the enhancement of research and development learning center is needed in bringing a better knowledge and improvise their daily work routines and at last will reflect productivity. Training not only ensures that employees and managers can perform their jobs competently, but it is also may create a productive environment this increases the satisfaction of their nature of work. Last but not least, the impact of lean culture also will spur to the better nature of work in organization. 
Lean cultures will not just be addressing the need to pursue improvements in individuals but it is also meant for the company through waste removal and innovation culture. This leader engagement in lean setting is more than just walking around to ask how things are going done, but they actively engaging and empowering the worker to identify, resolve defects and eliminating waste. Example of measure that can be taken is work on teambuilding and communicate the structure of culture change to get them involved in the real situation and working on solutions of the issues arise. All in all, this finding is only covered on selected automotive manufacturing in Malaysia, thus it may have some limitation with regards to generalizability for a whole organization in Malaysia.

\section{References}

[1] C. S. Long and L. Y. Thean, “Employees’ Turnover Intention: A Leadership Issue?,” Int. J. Futur. Comput. Commun., vol. 1, no. 3, p. 229, 2012.

[2] C. Wilson, "Retaining good people through a focus on talent and purpose: Proper inductions make employees feel as though they truly belong," Hum. Resour. Manag. Int. Dig., 2012.

[3] E. Yeong, "Average Job Turnover for a Person is $2 \frac{1}{2}$ Years," The Sun Daily, 2017. [Online]. Available: http://www.thesundaily.my/news/2017/07/20/aveage-jobturnover- person-21/2-years.

[4] H. Szymanski, "Scheneider Downs \& Co., Inc.," Schneider Downs Web site, 2015. [Online]. Available: https: //www.schneiderdowns.com/HR_auto.

[5] A. Wilson, "Employee turnover costs dealers billions," 2017. [Online]. Available: http://www.autonews.com/article/20170123/RETAIL06/301239850/employee-turnovercostsdealers billions.

[6] S. Clarke, "The effect of work environment, job communication and safety attitudes on accidents and unsafe behavior," Pers. Rev., vol. 35, no. 4, pp. 413-430, 2006.

[7] S. Aydogdu and B. Asikgil, "An empirical study of the relationship among job satisfaction, organizational commitment and turnover intention," Int. Rev. Manag. Mark., vol. 1, no. 3, p. 43, 2011.

[8] E. Medina, "Job satisfaction and employee turnover intention: what does organizational culture have to do with it?" Columbia university, 2012.

[9] D. Sulastiningtiyas and B. M. Nilasari, "The Effect Of Leadership Style, Work Environment, And Organizational Motivation On Employee Performance With Job Satisfaction As Variable Mediating,” Bus. Entrep. Rev., vol. 18, no. 2, pp. 93-114, 2019.

[10] R. B. Winston Jr and D. G. Creamer, Improving Staffing Practices in Student Affairs. The JosseyBass Higher and Adult Education Series. ERIC, 1997.

[11] A. S. Alkhateri, A. E. Abuelhassan, G. S. A. Khalifa, M. Nusari, and A. Ameen, "The Impact of perceived supervisor support on employees turnover intention: The Mediating role of job satisfaction and affective organizational commitment," Int. Bus. Manag., vol. 12, no. 7, pp. 477492, 2018.

[12] I. K. Tuzun and R. A. Kalemci, "Organizational and supervisory support in relation to employee turnover intentions," J. Manag. Psychol., 2012.

[13] A. Shukla, "The potential cause of employee turnover: immediate supervisor," J. Res. Commer. Manag., vol. 4, no. 1, pp. 38-41, 2015.

[14] P. E. Spector, "Measurement of human service staff satisfaction: Development of the Job Satisfaction Survey," Am. J. Community Psychol., vol. 13, no. 6, pp. 693-713, 1985.

[15] L. Jared, "Nature of Work vs. Level of Work. Small Business," Chron.com, 2019. [Online]. Available: http://smallbusiness.chron.com/nature-work-vslevel- work-33710.html.

[16] P. Sukriket, "The relationship between job satisfaction and turnover intention of Thai software programmers in Bangkok, Thailand," AU J. Manag., vol. 12, no. 2, pp. 42-52, 2014.

[17] A. Ahmad, "The relationship among job characteristics organizational commitment and employee turnover intentions," J. Work. Manag., 2018.

[18] R. Hassan, "Factors influencing turnover intention among technical employees in Information 
technology organization: A Case of XYZ (M) SDN. BHD,” Int. J. Arts Commer., vol. 3, no. 9, pp. 120-137, 2014.

[19] H. G. Heneman, "III, \& Judge, TA (2000). Compensation attitudes," Compens. Organ. Curr. Res. Pract., pp. 61-103.

[20] C.-C. Lee, S.-H. Huang, and C.-Y. Zhao, "A study on factors affecting turnover intention of hotel empolyees," Asian Econ. Financ. Rev., vol. 2, no. 7, p. 866, 2012.

[21] T. M. Hayes, "Demographic characteristics predicting employee turnover intentions," 2015.

[22] S. Iqbal, L. Guohao, and S. Akhtar, "Effects of job organizational culture, benefits, salary on job satisfaction ultimately affecting employee retention," Rev. Public Adm. Manag., vol. 5, no. 3, pp. $1-7,2017$.

[23] L.-M. Hung, Y.-S. Lee, and D.-C. Lee, "The Moderating Effects of Salary Satisfaction and Working Pressure on the Organizational Climate, Organizational Commitment to Turnover Intention.," Int. J. Bus. Soc., vol. 19, no. 1, 2018.

[24] A. J. Todd, "Industry and Society-A Sociological Appraisal of Modern Industrialisation," New York H. Holt Co., 1933.

[25] R. Tinwala and U. N. Biswas, "Perceived Sustainability Practices, Turnover Intentions, and Organizational Identification in Hotel Industries," Manag. J. Sustain. Bus. Manag. Solut. Emerg. Econ., vol. 25, no. 1, pp. 1-11, 2020.

[26] M. Javed, M. Rafiq, M. Ahmed, and M. Khan, "Impact of HR practices on employee job satisfaction in public sector organizations of Pakistan," Interdiscip. J. Contemp. Res. Bus., vol. 4, no. 1, pp. 348-363, 2012.

[27] S. Liu, E. Gyabeng, G. Joshua Atteh Sewu, N. K. Nkrumah, and B. Dartey, "Occupational Health and Safety and Turnover Intention in the Ghanaian Power Industry: The Mediating Effect of Organizational Commitment," Biomed Res. Int., vol. 2019, 2019.

[28] C. F. C. Bothma and G. Roodt, "The validation of the turnover intention scale," SA J. Hum. Resour. Manag., vol. 11, no. 1, pp. 1-12, 2013.

[29] J. San Park and T. H. Kim, "Do types of organizational culture matter in nurse job satisfaction and turnover intention?," Leadersh. Heal. Serv., 2009.

[30] G. Azanza, J. A. Moriano, F. Molero, and J.-P. L. Mangin, "The effects of authentic leadership on turnover intention," Leadersh. Organ. Dev. J., 2015.

[31] S. E. Mbah and C. O. Ikemefuna, "Job satisfaction and employees' turnover intentions in total Nigeria plc," Lagos State. Int. J. Humanit. Soc. Sci., vol. 2, no. 14, pp. 275-287, 2012.

[32] N. Ncede, "Factors contributing to employee turnover intention at a selected company in the Cape Town clothing industry," Cape Penins. Univ. Technol., 2013.

[33] V. M. Njeru, "A Survey of Voluntary Turnover Intentions of Information Technology Professionals in Kenya." United States International University-Africa, 2014.

[34] U. Sekaran and R. Bougie, Research methods for business: A skill building approach. John Wiley \& Sons, 2016.

[35] S. O. Adebayo and S. O. Ogunsina, "Influence of supervisory behaviour and job stress on job satisfaction and turnover intention of police personnel in Ekiti State," J. Manag. Strateg., vol. 2, no. 3, p. 13, 2011.

[36] Z. Ikatrinasari, L. Prayogo, and S. Ariyanti, "Analysis of turnover intention power factors: A case study of retail company in Jakarta," Manag. Sci. Lett., vol. 8, no. 10, pp. 1097-1102, 2018.

[37] T. R. Chepchumba and B. D. Kimutai, "The relationship between employee compensation and employee turnover in small businesses among Safaricom dealers in Eldoret municipality, Kenya," Int. J. Econ. Commer. Manag., vol. 5, no. 2, pp. 490-501, 2017. 